\title{
Resolving impurities in atomic layer deposited aluminum nitride through low cost, high efficiency precursor design
}

Sydney C. Buttera*a, Polla Rouf ${ }^{\mathrm{b}}$, Petro Deminskyi ${ }^{\mathrm{b}}$, Nathan J. O’Brien ${ }^{\mathrm{b}}$, Henrik Pedersen ${ }^{\mathrm{b}}$, Seán T. Barrya

aDepartment of Chemistry, Carleton University, Ottawa, Ontario K1S 5B6, Canada

bDepartment of Physics, Chemistry, and Biology, Linköping University, Linköping SE-58158, Sweden

*sydney.buttera@carleton.ca

\begin{abstract}
A heteroleptic amidoalane precursor is presented as a more suitably designed candidate to replace trimethylaluminum (TMA) for atomic layer deposition of aluminum nitride (AIN). The lack of C-AI bonds and the strongly reducing hydride ligands in $\mathrm{AlH}_{2}\left(\mathrm{NMe}_{2}\right)(1)$ were specifically chosen to limit impurities in target aluminum nitride (AIN) films. Compound 1 is made in a high yield, scalable synthesis involving lithium aluminum hydride and dimethylammonium chloride. It has a vapour pressure of 1 Torr at $40^{\circ} \mathrm{C}$ and evaporates with negligible residual mass in thermogravimetric experiments. Ammonia $\left(\mathrm{NH}_{3}\right)$ plasma and 1 in an atomic layer deposition (ALD) process produced crystalline AIN films above $200{ }^{\circ} \mathrm{C}$ with an Al: $\mathrm{N}$ ratio of 1.04 . Carbon and oxygen impurities in resultant AIN films were reduced to $<1 \%$ and $<2 \%$, respectively. This rational precursor design can improve the material quality of AIN films compared to the industrial standard trimethylaluminum and could reduce material cost by up to 2 orders of magnitude.
\end{abstract}




\section{Introduction}

Aluminum nitride (AIN) is a technologically important wide bandgap (6.2 eV) semiconductor which has applications as a dielectric layer and in light-emitting diodes. ${ }^{1}$ Applications in semiconductor technology require AIN to be deposited as a thin film with very high crystalline quality and precise control over incorporated impurities. This is routinely achieved by chemical vapour deposition (CVD) at $800-1100{ }^{\circ} \mathrm{C}$ using trimethylaluminum (TMA) and ammonia as precursors. Due to increasingly smaller and more complex device morphologies being explored, atomic layer deposition (ALD) is a valuable and necessary thin film deposition technique to employ for next generation electronic devices. ALD is a subset of CVD, but uses a sequential pulsing of the precursors to allow a deposition chemistry fully relying only on surface-limited and self-terminating chemical reactions. This gives ALD precise thickness control down to the Ångström level, but also limits the useable surface temperatures for ALD to a range where the formed monolayers are thermally stable, typically below $350^{\circ} \mathrm{C}$.

While TMA is the textbook precursor to deposit aluminum oxide $\left(\mathrm{Al}_{2} \mathrm{O}_{3}\right)$ by $A L D$, it is less suited to deposit AIN by ALD. Many ALD processes using TMA report carbon impurities in deposited films on the order of $3-6 \%,{ }^{2-4}$ which originate from the direct metal-carbon bonds present in this precursor. ${ }^{3}$ The thermodynamic driving force to form $\mathrm{Al}_{2} \mathrm{O}_{3}\left(\Delta \mathrm{G}_{\mathrm{f}}{ }^{\circ}=-1582 \mathrm{~kJ} / \mathrm{mol}\right)$ is much higher than the driving force to form $\operatorname{AIN}\left(\Delta \mathrm{G}_{\mathrm{f}}{ }^{\circ}=-287 \mathrm{~kJ} / \mathrm{mol}\right),{ }^{5}$ meaning that the $\mathrm{Al}-\mathrm{C}$ bonds in the TMA molecule are more prone to be a source of carbon impurities during AIN deposition, compared to during $\mathrm{Al}_{2} \mathrm{O}_{3}$ deposition. Although TMA is readily available and well-studied, it does not deposit AIN films with impurity levels low enough for electronic device quality AIN. Here we show how deposition of AIN can be improved through better precursor design.

ALD precursors must not only be volatile and contain the target atoms, but they should also be designed to promote a surface chemistry that prevents film impurities as efficiently as possible. Given the low thermodynamic driving force to form AIN, the Al precursor molecule should have Al-N bonds rather than $\mathrm{Al}-\mathrm{C}$ bonds to support the formation of AIN and to reduce the source of impurities 
coming from atoms bonded to the $\mathrm{Al}$ in the precursor. This study emphasizes the importance of ligand-metal bonding in an ALD precursor.

The oxyphilic nature of AIN, denoted by the significantly higher $\Delta \mathrm{G}_{\mathrm{f}}^{\circ}$ for $\mathrm{Al}_{2} \mathrm{O}_{3}$ compared to AIN above, means that AIN will be extremely prone to incorporate any background oxygen atoms present in the ALD reactor into the growing film. One can therefore either limit the depositions to sophisticated ALD reactor configurations with extremely low oxygen background levels, ${ }^{6}$ or build oxygen scavenging properties into the precursor. We previously used TMA as a template to design a homoleptic analogue precursor, replacing all methyl grounds with amide ligands; tris(dimethylamido)aluminum(III) was used to deposit $\mathrm{Al}_{2} \mathrm{O}_{3}$ by $\mathrm{ALD}$ with $\mathrm{C}$ contamination of less than $1 \% .{ }^{7}$ We have presently amended the precursor design to prevent oxygen incorporation in deposited AIN films by replacing two of the amide ligands with hydride ligands. We hypothesized that these hydride ligands will provide reducing surface conditions to prevent oxidation of the AIN film during film growth. The evolution of this precursor design employed a straightforward, low-cost synthesis and resulted in the precursor $\mathrm{AlH}_{2}\left(\mathrm{NMe}_{2}\right)$ (1). Here, we demonstrate its thermal properties and ability to deposit AIN, with very low levels of impurities, by ALD.

\section{Experimental}

Compound 1 was synthesized in an $\mathrm{N}_{2}$-filled glovebox using an adapted literature procedure from 1960. ${ }^{8}$ Dimethylammonium chloride $\left(\mathrm{Me}_{2} \mathrm{NH}_{2} \mathrm{Cl}\right)$ was dried under vacuum and ether was dried over $4 \AA$ sieves prior to use. Lithium aluminum hydride $\left(\mathrm{LiAlH}_{4}\right)(4.20 \mathrm{~g}, 109 \mathrm{mmol})$ was added to a 250 $\mathrm{mL}$ round-bottomed flask with $\sim 75 \mathrm{~mL}$ of ether and stirred with a magnetic stir bar. $\mathrm{Me}_{2} \mathrm{NH}_{2} \mathrm{Cl}(8.60$ g, $105 \mathrm{mmol})$ was cooled $\left(-35^{\circ} \mathrm{C}\right)$, then added scoop-wise to the $\mathrm{LiAlH}_{4}$ suspension. The mixture bubbled vigorously upon sequential additions and the resultant solution stirred overnight at room temperature. The solution was filtered through a medium fritted filter and the volume was reduced under vacuum to produce a white solid $(6.25 \mathrm{~g}, 81 \%$ unpurified yield). 
Thermogravimetric analysis (TGA) experiments were performed using a TGA Q500 tool in an $\mathrm{N}_{2}$ filled glovebox. The sample Pt pan was loaded with $\sim 10 \mathrm{mg}$ of precursor and the furnace was heated at a rate of $10^{\circ} \mathrm{C} / \mathrm{min}$ to $500^{\circ} \mathrm{C}$.

Differential scanning calorimetry (DSC) experiments were performed on a TA Instruments DSC Q10 tool. A sample of $0.200-0.500 \mathrm{mg}$ of 1 was prepared in a sealed aluminum pan in an $\mathrm{N}_{2}-$ filled glovebox. The sample of 1 and a blank reference pan were heated at a rate of $10{ }^{\circ} \mathrm{C} / \mathrm{min}$ to $400{ }^{\circ} \mathrm{C}$.

ALD experiments were performed on a hot-wall Picosun R-200 tool with a Litmas remote ICP plasma source. The operating pressure was maintained at 4 mbar under a continuous flow of $\mathrm{N}_{2}(99.999 \%$ and further purified with getter filters to remove residual moisture), which was also used as a purge gas. AIN films were deposited on $2.5 \mathrm{~cm} \times 2.5 \mathrm{~cm}$ Si coupons. The substrates were loaded into the reactor onto a heated substrate holder and the system was heated to $450{ }^{\circ} \mathrm{C}$ for 120 minutes before each run with a continuous $\mathrm{N}_{2}$ flow $(300 \mathrm{sccm})$ to minimize the oxygen content in the chamber. The $\mathrm{NH}_{3}$ (AGA/Linde, 99.999\%) plasma used as the nitrogen source was an $\mathrm{Ar}$ (99.999\%, further purified with a getter filter to remove residual moisture)/ $\mathrm{NH}_{3}(100 / 75 \mathrm{sccm})$ mixture, ignited using a plasma power of $2800 \mathrm{~W}$. These plasma parameters were previously investigated to be optimal for our reactor and deposition of nitrides. ${ }^{9}$ Compound 1 was pulsed in the range of 2 to 16 seconds to determine saturative behaviour, while $\mathrm{NH}_{3}$ plasma was pulsed for 12 seconds. After each precursor pulse, the system was purged with a 10 second pulse of $\mathrm{N}_{2}$.

PANalytical EMPYREAN MRD XRD with a Cu-anode X-ray tube and 5-axis (x-y-z-v-u) sample stage operating at $45 \mathrm{kV}$ and $40 \mathrm{~mA}$ was used in grazing-incidence X-ray diffraction (GIXRD) mode with $0.5^{\circ}$ incident angle to analyze film crystallinity. Stress and strain were estimated using GIXRD data for diffraction peaks; values of $\sin ^{2} \psi$ and $\varepsilon$ were obtained using X'Pert Stress software. Kratos AXIS Ultra DLD X-ray photoelectron spectroscopy (XPS) equipped with an Ar sputtering source $(0.5 \mathrm{keV})$ was used to analyze film composition. CasaXPS was used to analyze XPS data. High-resolution scans were fitted by Gaussian-Laurentius functions and Shirley 
background. Scanning electron microscopy (SEM) using a LEO 1550 tool operating at $10 \mathrm{kV}$ was used for film surface imaging and film thickness measurements.

\section{Results and discussion}

Compound 1 has been modified from a TMA and subsequent homoleptic amide framework for the sake of logic, simplicity, and low expense, while additionally building in the potential for the existence of a reducing environment during film deposition. It is the intended design that this will affect the surface chemistry during AIN growth, and that the quality of AIN films produced should be a direct reflection of the use of this precursor. The synthesis of 1 employs lithium aluminum hydride $\left(\mathrm{LiAlH}_{4}\right)$ and dimethylammonium chloride $\left(\mathrm{Me}_{2} \mathrm{NH}_{2} \mathrm{Cl}\right)$, two very inexpensive and readily available starting materials. The reaction proceeds with the evolution of hydrogen gas and the precipitation of lithium chloride, both of which act as thermodynamic driving forces for the reaction to go to completion:

$$
\mathrm{LiAlH}_{4}+\mathrm{Me}_{2} \mathrm{NH}_{2} \mathrm{Cl} \rightarrow \mathrm{AlH}_{2}\left(\mathrm{NMe}_{2}\right)+2 \mathrm{H}_{2}+\mathrm{LiCl}
$$

This adapted 60-year-old preparation is elegant and straightforward, preceding the invention of ALD itself, and easily produces a precursor that is valuable for this application. Compound $\mathbf{1}$ is a nonpyrophoric solid that can be synthesized in two hours at a material cost of $\sim \$ 1$ per gram, without the need for further purification. The high crude yield and low cost of reactants, as well as the straightforward one-pot, single step synthesis makes compound 1 an accessible and inexpensive ALD precursor.

The TGA ramp experiment for 1 (Figure 1) demonstrates that it is a volatile and thermally stable precursor. The volatilization curve shows an exponential mass loss with no visible signs of decomposition and negligible residual mass. Its 1 Torr temperature was calculated to be $40{ }^{\circ} \mathrm{C}$ using mass loss derivative data. ${ }^{10}$ Generally, precursors that generate 1 Torr of vapour pressure lower than $100{ }^{\circ} \mathrm{C}$ are considered very volatile and easy to use in a variety of ALD processes. Differential scanning calorimetry (DSC) characterization showed an exotherm at $210^{\circ} \mathrm{C}$ that is likely 
attributed to decomposition of 1 . With a 1 Torr vapour pressure of $40^{\circ} \mathrm{C}$, this gives a thermal range in which to establish an ALD process of $170^{\circ} \mathrm{C}$, allowing 1 flexibility in process development.

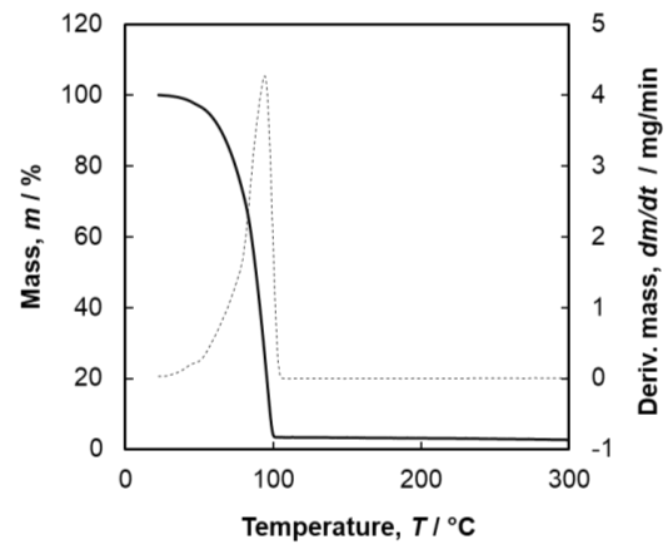

Figure 1: TGA ramp of compound $\mathbf{1}$, showing a low onset of volatilization and $1.3 \%$ residual mass.

Deposition of AIN from 1 was straightforward using an ammonia plasma as the second precursor. The saturation curve for 1 in ALD experiments to produce AIN is presented in Figure 2a. Saturative growth - the defining characteristic of an ALD deposition - was observed after $8 \mathrm{~s}$ of exposure of 1. Experiments run at $100^{\circ} \mathrm{C}$ do not exhibit saturative ALD behaviour, which can be attributed to precursor condensation at the surface.

SEM micrographs (Figure 2c-d) show that ALD-grown AIN films are uniform and dense. Experiments performed at $100{ }^{\circ} \mathrm{C}$ (Figure 2a) show droplets present on the surface, which confirms that precursor condenses on the substrate at lower deposition temperatures. Measurements of AIN deposited at $200{ }^{\circ} \mathrm{C}$ demonstrated an Al: $\mathrm{N}$ ratio of 1.04 , indicating near stoichiometric AIN. 

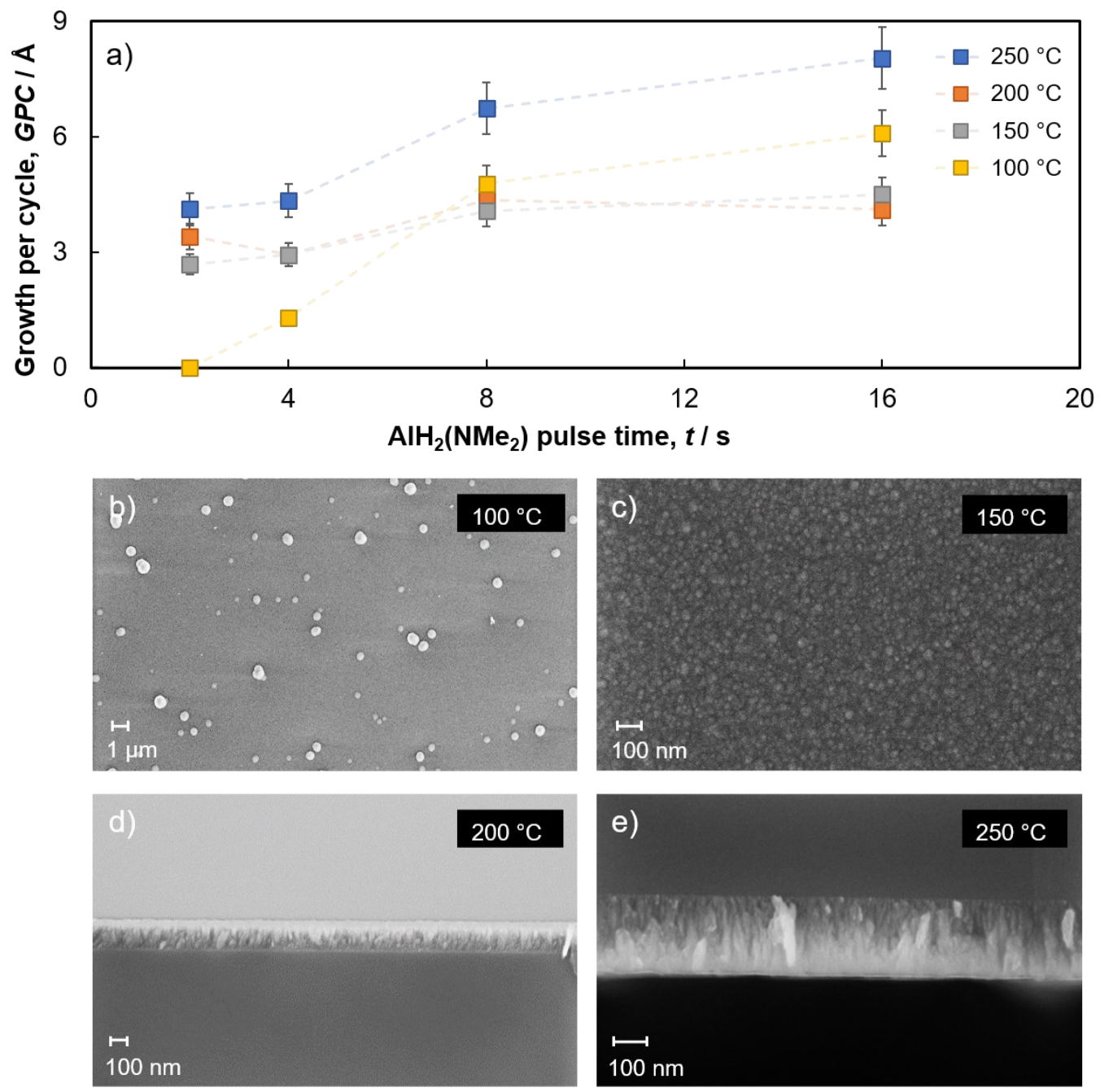

Figure 2: a) Saturation curve for 1 in ALD process with $\mathrm{NH}_{3}$ plasma, and SEM micrographs of AIN films deposited at b) $100^{\circ} \mathrm{C}$, c) $150^{\circ} \mathrm{C}$, d) $200^{\circ} \mathrm{C}$, and e) $250{ }^{\circ} \mathrm{C}$.

Saturation occurs during depositions at $150^{\circ} \mathrm{C}$ and $200^{\circ} \mathrm{C}$, with a GPC of $4.3 \pm 0.4 \AA$. This is significantly higher than previous literature examples using TMA and $\mathrm{NH}_{3}$ plasma, which report GPCs of $0.9 \AA .{ }^{11,12}$ The unit cell height of hexagonal AIN is $5.017 \AA$ in the c-direction. ${ }^{13}$ The XRD analysis of the films (see below) indicate that the AIN grew along the c-direction, with the GPC lying just outside the lattice parameters for hexagonal AIN, considering measurement error.

The precursor is likely anchored through the hydride $(\mathrm{pKa}=35)$ reacting with a surface proton to produce dihydrogen (Figure 3). This would be similar to TMA (pKa estimated to be $\sim 50$ ) 
chemisorption by the elimination of methane, and so might, like TMA, proceed through either one (Figure 3a) or two eliminations (Figure 3b). ${ }^{14}$ Notably different from nucleation at a hydroxyl is that the surface nucleation point in this case can be doubly protonated $\left(\|-\mathrm{NH}_{2}\right)$, allowing for two eliminations at one nucleation site (Figure 3c).

a)

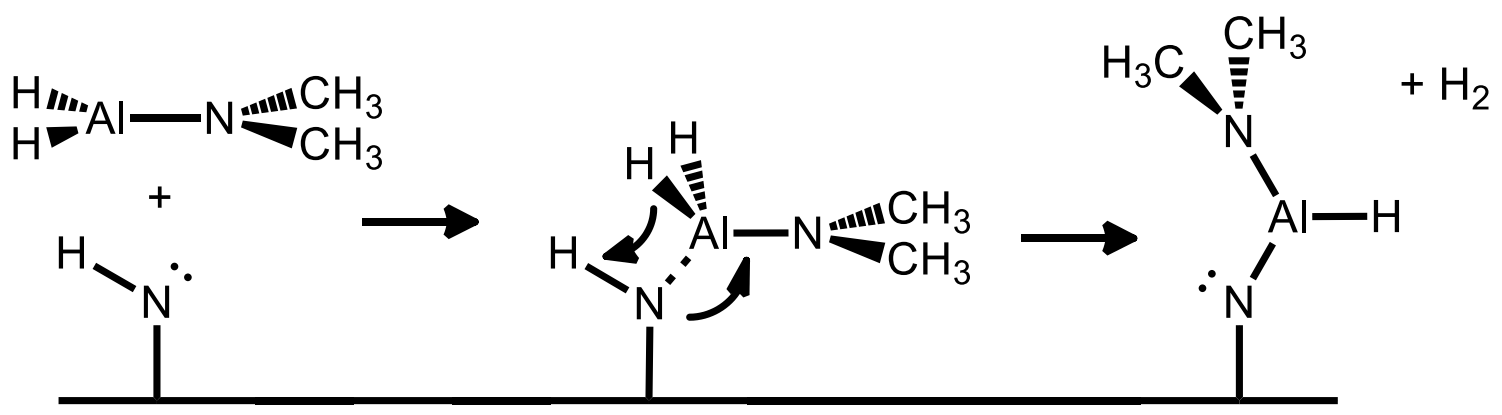

b)

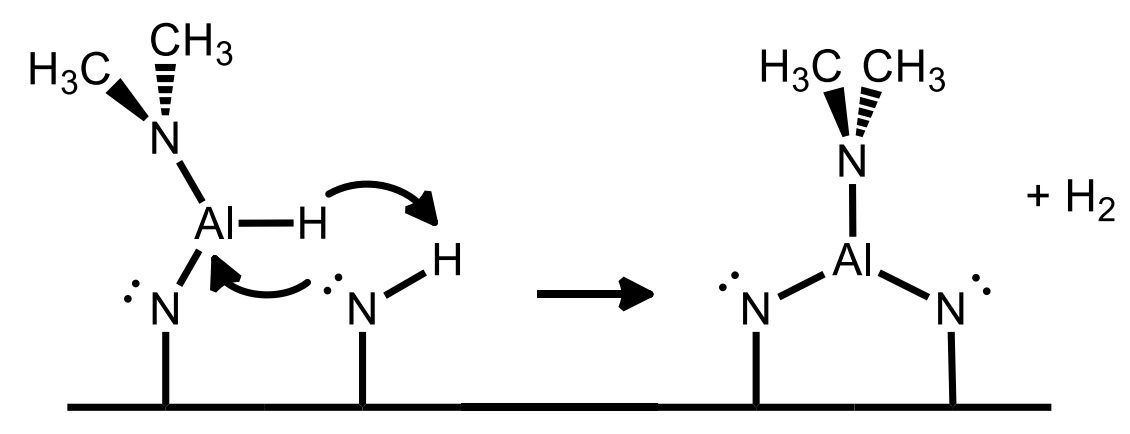

c)

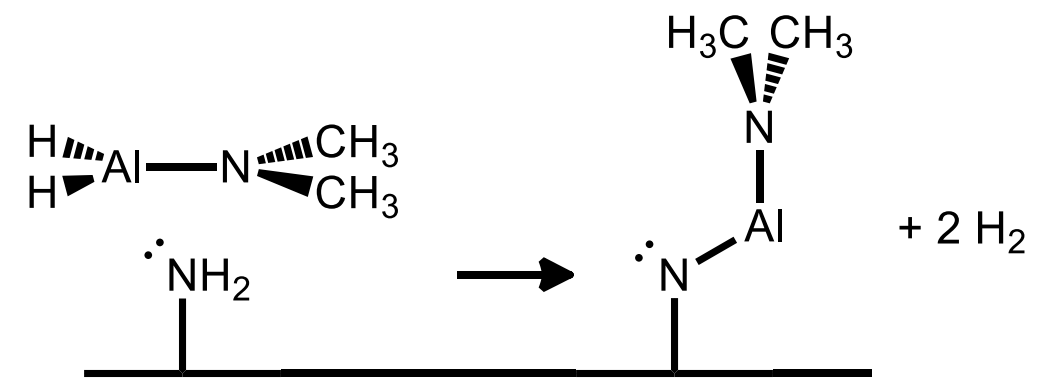

Figure 3: The chemisorption of 1 at a growing nitride surface through dihydrogen elimination(s).

Interestingly, the chemistry of Figure 3 applies for the elimination of methane from TMA nucleation as well, and so cannot account for the difference in GPC. The larger growth per cycle of 1 might originate from the existence of 1 as a trimer, ${ }^{8}$ which could allow it to chemisorb in a higher 
surface density than TMA. The surface chemistry of 1 merits investigating in a subsequent study to determine the cause of this high GPC.

Figure 4a shows GIXRD data for AIN films deposited between $100^{\circ} \mathrm{C}$ and $250^{\circ} \mathrm{C}$ after 500 cycles of deposition. Films deposited at 200 and $250^{\circ} \mathrm{C}$ showed the strongest peaks corresponding to crystalline hexagonal AIN; both the (100) and (002) peaks were observed. These peaks were also visible for the samples deposited at $150{ }^{\circ} \mathrm{C}$, but with lower intensity. Crystallinity of these AIN films was seen to increase both with increased deposition temperature and number of cycles; low temperature depositions $\left(100^{\circ} \mathrm{C}\right)$ do not appear to be crystalline, and crystallinity of AIN films grown was not observed after only 200 deposition cycles, even at higher deposition temperatures. When AIN was deposited on $\mathrm{SiC}$ (shown in the left inset of Figure 4a), films were not epitaxial, though their crystallinity improved, and a very strong (103) peak was observed. 

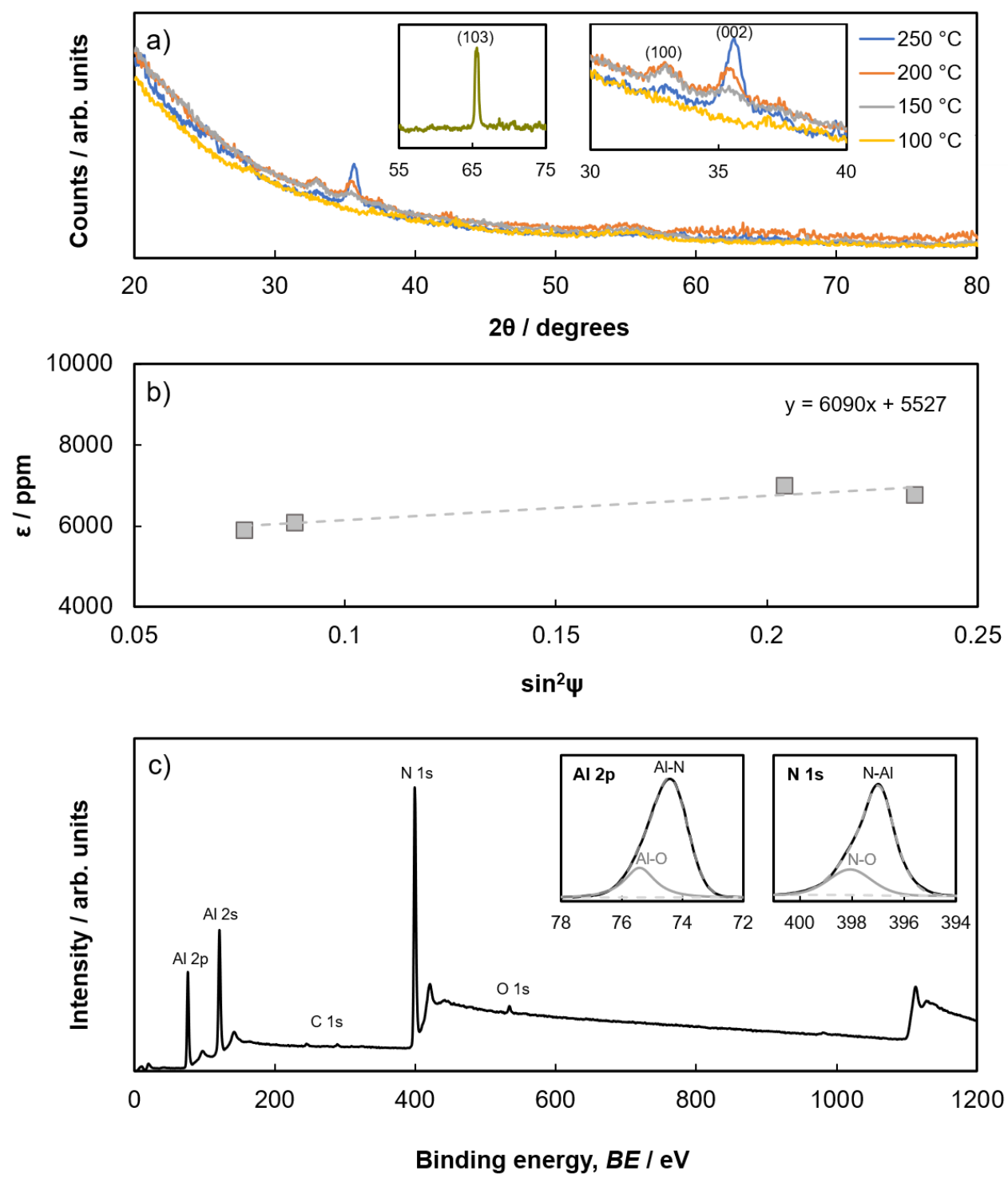

Figure 4: a) GIXRD plot of deposited AIN films (left inset for AIN deposited on $\mathrm{SiC}$ ), b) $\sin ^{2} \psi$ vs. $\varepsilon$ plot to calculate film strain, c) XPS survey scan of AIN film deposited at $200^{\circ} \mathrm{C}$ and inset highresolution scans for $\mathrm{Al} 2 \mathrm{p}$ and $\mathrm{N} 1 \mathrm{~s}$.

Film composition was studied by XPS (Figure 4c) after sputtering to clean incidental contamination from the surface and showed very low impurity levels. High-resolution peaks were fitted for $\mathrm{Al} 2 \mathrm{p}$ at 74.7 and $75.5 \mathrm{eV}$ as representing $\mathrm{Al}-\mathrm{N}$ and $\mathrm{Al}-\mathrm{O}$ bonds, respectively, while the $\mathrm{N}$ 1s spectrum was fitted for $\mathrm{N}-\mathrm{Al}$ and $\mathrm{N}-\mathrm{O}$ bonds at 397.9 and $399.4 \mathrm{eV}$. Importantly, for AIN deposited at $200{ }^{\circ} \mathrm{C}$ (Al:N ratio of 1.04), the observed impurity levels of carbon and oxygen were 0.7 
and 1.7 atomic $\%$, respectively. This indicates that metal-nitrogen and metal-hydride bonds designed into the precursor successfully respectively reduced carbon and oxygen contamination in AIN films. This is especially noteworthy when other processes using $\mathrm{TMA}$ and $\mathrm{NH}_{3}$ plasma have employed plasma pulse lengths of 40 seconds ${ }^{15-18}$ in order to reduce impurities in AIN films.

Other AIN films deposited from TMA using both ammonia and hydrogen plasmas showed similar impurity levels to films deposited from 1 and ammonia plasma, ${ }^{19}$ which supports the hypothesis that the inclusion of the hydride ligands in the design of 1 would help direct the surface chemistry. The effect of including hydrogen radicals in the plasma to maintain a reducing atmosphere and scavenge impurities at the deposition surface showed the same effect on surface chemistry as using hydride ligands in compound $\mathbf{1}$. This is a gratifying result, since it further demonstrates that judicious precursor design can be an effective tool for process design, and that a thoughtfully designed precursor alone can improve material properties. These significant improvements can be made without increasing deposition time or reagents due to the addition of a second plasma pulse.

The stress and strain of the AIN films were estimated using GIXRD data from an $\varepsilon-\sin ^{2} \psi$ plot using a previously reported method, ${ }^{20}$ shown in Figure 4b. The positive slope of $6090 \mathrm{ppm}$ indicates a tensile strain of $0.61 \%$ and tensile stress was calculated as a range between 1.50 and $1.67 \mathrm{GPa} ;{ }^{13,20}$ it is expected for tensile strain and stress to exist in these AIN films due to their large lattice mismatch compared to the Si substrate.

$\mathrm{AlH}_{2}\left(\mathrm{NMe}_{2}\right)$ (1) is easy to synthesize on a lab scale (tens of grams) in less than two hours at a materials cost of $\sim \$ 1 /$ gram (USD) without any requirements for further purification; the cost of the synthesis can be halved to $\sim \$ 0.50 /$ gram if reagents are purchased on a larger (kilogram) scale. This is significant in comparison to the material cost of TMA from a catalogue, which is available for purchase for $\sim \$ 70 / \mathrm{g}$ per gram (25 $\mathrm{g}$ in a bubbler). Although this comparison strictly highlights the materials cost difference between these two precursors from the point of view of a research laboratory, it emphasizes the fact that employing 1 as an ALD precursor compared to TMA can be significantly more accessible to research groups while also producing high quality AIN films. It is 
especially important to consider the GPC of AIN achieved using 1, which is three to four times higher than what is achieved using TMA.

\section{Conclusions}

This work emphasizes the importance of developing thoughtfully designed alternative precursors to TMA for Al-based ALD. The new ALD precursor $\mathrm{AlH}_{2}\left(\mathrm{NMe}_{2}\right)$ (1) produces excellent AIN films in a process with $\mathrm{NH}_{3}$ plasma with measured carbon impurities significantly lower than many processes reported using TMA due to the Al-N bonds designed into the precursor, as well as reduced oxygen contamination due to the employment of the hydride ligand. Using a TMA framework is an excellent way to design and synthesize alternative precursors better suited to AIN deposition by ALD and could demonstrate significant cost-savings if employed on a larger scale.

A simple shift away from TMA towards 1 has shown that if smart precursor design becomes an integral step of developing new deposition processes, the quality of ALD-grown films and their subsequent applications can be improved. Precursors should be synthesized to be maximally effective and efficient, and using 1 to deposit AIN is a demonstration of how well this can work.

\section{Conflicts of Interest}

There are no conflicts to declare.

\section{Acknowledgements}

This project was funded by the Swedish foundation for Strategic Research through the project "Time-resolved low temperature CVD for III-nitrides" (No. SSF-RMA 15-0018). S.C.B. acknowledges the Vinnova VINNMER Marie Curie incoming mobility program for funding research visits to Linköping University (Vinnova Grant No. 2015-03714). 


\section{References}

1 A. F. Belyanin, L. L. Bouilov, V. V. Zhirnov, A. I. Kamenev, K. A. Kovalskij and B. V. Spitsyn, Diam. Relat. Mater., 1999, 8, 369-372.

2 M. Broas, P. Sippola, T. Sajavaara, V. Vuorinen, A. Pyymaki Perros, H. Lipsanen and M. Paulasto-Kröckel, J. Vac. Sci. Technol. A Vacuum, Surfaces, Film., 2016, 34, 041506.

3 J. Jokinen, P. Haussalo, J. Keinonen, M. Ritala, D. Riihelä and M. Leskelä, Thin Solid Films, 1996, 289, 159-165.

4 H. Van Bui, F. B. Wiggers, A. Gupta, M. D. Nguyen, A. A. I. Aarnink, M. P. de Jong and A. Y. Kovalgin, J. Vac. Sci. Technol. A Vacuum, Surfaces, Film., 2015, 33, 01 A111.

5 D. R. Lide, G. Baysinger, L. I. Berger, R. N. Goldberg, H. V Kehiaian, K. Kuchitsu, D. L. Roth and D. Zwillinger, CRC Handbook of Chemistry and Physics, .

6 G. B. Rayner, N. O'Toole, J. Shallenberger and B. Johs, J. Vac. Sci. Technol. A, 2020, 38, 062408.

7 S. C. Buttera, D. J. Mandia and S. T. Barry, J. Vac. Sci. Technol. A Vacuum, Surfaces, Film., 2017, 35, 01B128.

8 J. K. Ruff and M. F. Hawthorne, J. Am. Chem. Soc., 1960, 82, 2141-2144.

9 P. Deminskyi, P. Rouf, I. G. Ivanov and H. Pedersen, J. Vac. Sci. Technol. A, 2019, 37, 020926.

10 G. V Kunte, S. A. Shivashankar and A. M. Umarji, Meas. Sci. Technol., 2008, 19, 025704.

11 L. Tian, S. Ponton, M. Benz, A. Crisci, R. Reboud, G. Giusti, F. Volpi, L. Rapenne, C. Vallée, M. Pons, A. Mantoux, C. Jiménez and E. Blanquet, Surf. Coatings Technol., , DOI:10.1016/j.surfcoat.2018.04.031.

12 S. Banerjee, A. A. I. Aarnink, R. van de Kruijs, A. Y. Kovalgin and J. Schmitz, Phys. status solidi, 2015, 12, 1036-1042.

13 D. Nilsson, E. Janzen and A. Kakanakova-Georgieva, J. Phys. D. Appl. Phys.

14 R. L. Puurunen, J. Appl. Phys., 2005, 97, 121301.

15 M. Alevli, C. Ozgit, I. Donmez and N. Biyikli, J. Cryst. Growth, 2011, 335, 51-57. 
16 H. Altuntas, C. Ozgit-Akgun, I. Donmez and N. Biyikli, Cit. J. Appl. Phys., 2015, 117, 155101.

17 M. Alevli, C. Ozgit, I. Donmez and N. Biyikli, Cit. J. Vac. Sci. Technol. A, 2012, 30, 21506.

18 M. Bosund, T. Sajavaara, M. Laitinen, T. Huhtio, M. Putkonen, V.-M. Airaksinen and H. Lipsanen, Appl. Surf. Sci., 2011, 257, 7827-7830.

19 L. Tian, S. Ponton, M. Benz, A. Crisci, R. Reboud, G. Giusti, F. Volpi, L. Rapenne, C. Vallée, M. Pons, A. Mantoux, C. Jiménez and E. Blanquet, Surf. Coatings Technol., 2018, 347, $181-190$.

20 P. Rouf, N. J. O’Brien, S. C. Buttera, I. Martinovic, B. Bakhit, E. Martinsson, J. Palisaitis, C.W. Hsu and H. Pedersen, J. Mater. Chem. C, 2020, 3, 1101-1134. 